\title{
Acute Treatment of Hypertensive Urgency
}

\author{
Anthony C. Breu, MD ${ }^{1,2 *}$, R. Neal Axon, MD, MSCR 3,4
}

\begin{abstract}
${ }^{1}$ Veterans Affairs Boston Healthcare System, West Roxbury, Massachusetts; ${ }^{2}$ Harvard Medical School, Boston, Massachusetts; ${ }^{3}$ Ralph H. Johnson VA Medical Center, Charleston Health Equity and Rural Outreach Innovation Center (HEROIC), Charleston, South Carolina; ${ }^{4}$ Department of Medicine, the Medical University of South Carolina, Charleston, South Carolina.
\end{abstract}

The "Things We Do for No Reason" (TWDFNR) series reviews practices which have become common parts of hospital care but provide little value to our patients. Practices reviewed in the TWDFNR series do not represent "black and white" conclusions or clinical practice standards but are meant as a starting place for research and active discussions among hospitalists and patients. We invite you to be part of that discussion.

\section{CLINICAL SCENARIO}

A 67-year-old man is hospitalized with community-acquired pneumonia. He has a history of hypertension and is prescribed two antihypertensive medications (amlodipine and chlorthalidone) as an outpatient. On the evening of hospital day two, he is found to have a blood pressure of 192/95 on a scheduled vital signs check. He reports no symptoms other than cough, which is not new or worsening. The covering hospitalist reviews the documented blood pressures since admission and notes that many have been elevated despite continuation of his home regimen. The patient's nurse inquires about treating the patient with additional "as-needed" antihypertensive medications.

\section{BACKGROUND}

Hypertensive crises are common in hospitalized patients, with approximately one in seven patients experiencing an episode of hypertensive emergency and/or hypertensive urgency. ${ }^{1}$ Hypertensive emergency is typically defined as (1) a systolic blood pressure $\geq 180 \mathrm{~mm} \mathrm{Hg}$ and/or a diastolic blood pressure $\geq 120 \mathrm{~mm} \mathrm{Hg}$ with (2) evidence of new or worsening end-organ damage. The organs most commonly affected by severe hypertension are the brain (headache, confusion, stroke), heart (chest pain, myocardial infarction, pulmonary edema), large blood vessels (aortic dissection), and kidneys (acute hypertensive nephrosclerosis). ${ }^{2}$ With hypertensive urgency, patients experience similarly elevated blood pressure but have no symptoms or signs suggesting acute end-organ damage. Acute treatment with intravenous (IV) or immediate-acting oral medications is common; a single-center study showed that $7.4 \%$ of hospitalized patients had an order for "as needed" IV hy-

*Address for correspondence: Anthony C. Breu, MD, 1400 VFW Parkway, Medical Service, West Roxbury MA 02132; Telephone: 857-203-5111; Fax: 857203-5549; E-mail: anthony.breu@va.gov

Published online first October 31, 2018

Received: March 2, 2018; Revised: June 18, 2018; Accepted: August 11, 2018

(c) 2018 Society of Hospital Medicine DOI 10.12788/jhm.3086 dralazine or labetalol, with $60.3 \%$ receiving at least one dose. ${ }^{3}$ Among internal medicine and family medicine trainees in one survey, nearly half reported that they would use IV medications in a scenario where an inpatient had an asymptomatic blood pressure above $180 \mathrm{~mm} \mathrm{Hg}^{4}$

\section{WHY YOU MIGHT THINK TREATING HYPERTENSIVE URGENCY IS NECESSARY}

Treating patients with hypertensive urgency is based on an assumption: If one does not treat immediately, something bad (ie, end-organ damage) will occur over the next few hours. Data from the 1930s showed that patients with untreated hypertensive emergency had a one-year mortality rate $>79 \%$ and a median survival of 10.4 months. ${ }^{5}$ More recent studies suggest that the in-hospital and one-year mortality for those with hypertensive emergency are $13 \%$ and $39 \%$, respectively. ${ }^{6}$ These data demonstrate that patients with hypertensive emergency are at risk in both the short- and long-term.

Patients with hypertensive urgency are also at increased risk for long-term morbidity and mortality. The one-year mortality for those experiencing an episode of hypertensive urgency is approximately $9 \% .{ }^{6}$ Given the concerns about poor outcomes, it remains a common practice in many facilities to acutely lower the blood pressure in patients with hypertensive urgency. This is highlighted by recommendations of a commonly used point-of-care medical resource, which suggests that "potential legal ramifications partially motivate lowering the blood pressure over several hours."7

\section{WHY TREATING HYPERTENSIVE URGENCY IS UNNECESSARY AND POTENTIALLY HARMFUL}

Concerns regarding overtreatment of hypertensive urgency relate to overestimated rates of hypertensive complications, the pathophysiology of hypertension itself, and the potential for adverse events related to treatment. Given that there are few trials examining hospitalized patients with hypertensive urgen$c y$, much of the data supporting a conservative approach are drawn from studies of outpatients or emergency department patients. In addition, there is little data suggesting that outcomes are different for patients presenting with a chief complaint of hypertensive urgency and those presenting with an alternate diagnosis but who are found to have blood pressures that meet the threshold for diagnosis of hypertensive urgency.

The landmark 1967 Veterans Affairs Cooperative Trial demonstrated the long-term benefits of treating patients with chronic hypertensive urgency. ${ }^{8}$ Importantly though, benefits 
accrued over a period of months to years, not hours. The time to the first adverse event in the placebo arm was two months, suggesting that even those with blood pressures chronically in the range of hypertensive urgency are unlikely to experience hyperacute (ie, within hours) events, even without treatment.

A more recent study, conducted by Patel et al., examined 58,836 patients seen in outpatient clinics and found to have blood pressures meeting the criteria for hypertensive urgency. ${ }^{9}$ This study included patients whose primary issue was hypertensive urgency and patients in whom the diagnosis was secondary. A total of 426 patients were referred to the hospital and only 100 (0.17\%) were subsequently admitted. At seven days, the rates of the primary outcome (a composite of myocardial infarction, stroke, and/or transient ischemic attack) were $0.1 \%$ in those sent home and $0.5 \%$ in those sent to the hospital. In those patients with a systolic blood pressure $\geq 220 \mathrm{~mm} \mathrm{Hg}$, two out of $977(0.2 \%)$ of those sent home and zero out of 81 of those sent to the hospital experienced the primary outcome. These data reinforce the message that, in patients with hypertensive urgency, rates of adverse events at seven days are low, even with extreme blood pressure elevation.

The human body has adapted to withstand wide variations in blood pressure. ${ }^{10}$ For example, through arteriolar constriction and reflex vasodilation, cerebral autoregulation maintains a constant cerebral blood flow within a wide range of perfusion pressures, ensuring that the brain is protected from higher mean arterial pressures. ${ }^{11}$ While this process is protective, over time the autoregulatory system becomes impaired, especially in patients with cerebrovascular disease. This places patients at risk for cerebral and/or cardiac ischemia with even slight drops in perfusion pressure. ${ }^{12,13}$ Indeed, in assessing treatment-related adverse events in a series of patients treated with intravenous nicardipine or nitroprusside for hypertensive emergency, Brooks and colleagues reported that 57\% (27 of 47) of patients had overly large reductions in blood pressure ( $>25 \%$ reduction in mean arterial pressure) within the first 30 minutes of treatment. ${ }^{14}$ Two patients had acute ischemic events attributed to treatment with antihypertensive medications. Myocardial infarction and stroke have both been reported, ${ }^{12}$ and medication classes such as calcium channel blockers (sublingual nifedipine in particular), beta-blockers (eg, labetolol), angiotensin-converting-enzyme inhibitors (eg, captopril), and clonidine have all been implicated in treatment-related adverse events. ${ }^{12,15-17}$ Another potential issue derives from the observation that blood pressures obtained in the hospital setting are often inaccurate, owing to inappropriate patient preparation, faulty equipment, and inadequate training of staff obtaining the measurement. ${ }^{18}$

National guidelines support a cautious approach to the treatment of hypertensive urgency. The seventh Report of the Joint National Committee on Detection, Evaluation, and Treatment of Hypertension, published in 2003, noted that "patients with markedly elevated BP but without acute target-organ damage usually do not require hospitalization, but they should receive immediate combination oral antihypertensive therapy" and that "there is no evidence to suggest that failure to aggressively lower BP in the [emergency department] is as- sociated with any increased short-term risk to the patient who presents with severe hypertension." JNC 7 also laments contemporary terminology: "Unfortunately, the term 'urgency' has led to overly aggressive management of many patients with severe, uncomplicated hypertension. Aggressive dosing with intravenous drugs or even oral agents, to rapidly lower BP is not without risk." ${ }^{19}$ The most recent JNC guideline does not comment on hypertensive urgency, ${ }^{20}$ and the 2017 American College of Cardiology/American Heart Association Guideline for the Prevention, Detection, Evaluation, and Management of High Blood Pressure in Adults argues that, "...there is no indication for referral to the emergency department, immediate reduction in BP in the emergency department, or hospitalization for [patients with hypertensive urgency]." ${ }^{21}$

\section{WHAT CLINICIANS SHOULD DO INSTEAD}

After it is confirmed that a patient has no end-organ damage (ie, the patient has hypertensive urgency, not emergency), treatable causes of hypertension should be assessed. In hospitalized patients, these include missed or held doses of outpatient medications, pain, nausea, alcohol and/or benzodiazepine withdrawal, delirium, and obstructive sleep apnea. ${ }^{22}$ If no remediable cause is identified, patients should be allowed to rest for at least 30 minutes without the administration of additional antihypertensive medications, after which time the blood pressure should be measured using the correct technique. ${ }^{2}$ Clinical trials have shown that rest is effective at lowering blood pressure in patients with hypertensive urgency. ${ }^{23,24}$ One study initially treated 549 emergency department patients with a 30 -minute rest period, after which time $32 \%$ of patients had responded (defined as a SBP $<180 \mathrm{~mm} \mathrm{Hg}$ and DBP $<110 \mathrm{~mm}$ $\mathrm{Hg}$, with at least a $20 \mathrm{~mm} \mathrm{Hg}$ reduction in baseline SBP and/ or a $10 \mathrm{~mm} \mathrm{Hg}$ reduction in DBP). ${ }^{23}$ Another study randomized 138 patients with hypertensive urgency to either rest or active treatment with telmisartan. Blood pressures were checked every 30 minutes for four hours. The primary endpoint (reduction of MAP of $10 \%-35 \%$ ) was similar in both groups $(68.5 \%$ in the rest group and $69.1 \%$ in the telmisartan group). ${ }^{24}$ Even if rest is ineffective, the risk-benefit ratio of acutely lowering blood pressure will typically favor withholding acute treatment in asymptomatic patients. If blood pressure remains consistently elevated, augmentation of the home regimen (eg, increasing the dose of their next scheduled antihypertensive) of oral medications may be warranted. Though not all agree with management of antihypertensives in hospitalized patients, ${ }^{25}$ acute hospitalizations afford an opportunity to modify and observe chronic hypertension. ${ }^{26}$

\section{RECOMMENDATIONS}

- Ensure that patients do not have symptoms and/or signs of end-organ damage. This can be done with a brief review of systems and a physical examination. In select cases, an electrocardiogram and a chest x-ray may be warranted.

- Search for common causes of treatable hypertension in hospitalized patients; these include pain, nausea, withdrawal syndromes, and holding of usual antihypertensive medications. 
- In those patients without symptoms and/or signs of end-organ damage, allow rest, followed by reassessment.

- Do not administer intravenous or immediate-acting oral antihypertensive medications to acutely lower blood pressure. Instead, address the issues raised in Recommendation \#2 and consider modifying the chronic oral antihypertensive regimen in patients who are uncontrolled as outpatients or who are not treated as outpatients. Coordinate early postdischarge follow-up for repeat blood pressure evaluation and continued modification of a patient's chronic antihypertensive regimen.

\section{CONCLUSION}

Although patients with hypertensive urgency are often treated with medications to acutely lower their blood pressure, there is no evidence to support this practice, and a strong pathophysiologic basis suggests that harm may result. The patient in the case described above should be allowed to rest for at least 30 minutes, with reevaluation of his blood pressure. If it remains elevated and no treatable secondary causes are found, the treating hospitalist should consider altering his chronic antihypertensive regimen to promote long-term blood pressure control.

Do you think this is a low-value practice? Is this truly a "Thing We Do for No Reason?" Share what you do in your practice and join in the conversation online by retweeting it on Twitter (\#TWDFNR) and liking it on Facebook. We invite you to propose ideas for other "Things We Do for No Reason" topics by emailingTWDFNR@hospitalmedicine.org.

Disclosures: The authors have no conflicts of interest.

\section{References}

1. Shorr AF, Zilberberg MD, Sun $X$, et al. Severe acute hypertension among inpatients admitted from the emergency department. J Hosp Med. 2012;7(3):203-210. doi: 10.1002/jhm.969.

2. Whelton PK, Carey RM, Aronow WS, et al. ACC/AHA/AAPA/ABC/ACPM/ AGS/APhA/ASH/ASPC/NMA/PCNA guideline for the Prevention, detection, evaluation, and management of High blood pressure in adults: A report of the American College of Cardiology/American Heart Association task force on clinical practice guidelines. Hypertension. 2017.

3. Weder $A B$, Erickson $S$. Treatment of hypertension in the inpatient setting: use of intravenous labetalol and hydralazine. J Clin Hypertens (Greenwich). 2010;12(1):29-33. doi: 10.1111/j.1751-7176.2009.00196.x

4. Axon RN, Garrell R, Pfahl K, et al. Attitudes and practices of resident physicians regarding hypertension in the inpatient setting. J Clin Hypertens (Greenwich). 2010;12(9):698-705. doi: 10.1111/j.1751-7176.2010.00309.x.

5. Keith NM, Wagener HP, Barker NW. Some different types of essential hypertension: their course and prognosis. Am J Med Sci. 1974;268(6):336-345. doi: 10.1097/00000441-197412000-00004.

6. Guiga H, Decroux C, Michelet P, et al. Hospital and out-of-hospital mortality in 670 hypertensive emergencies and urgencies. J Clin Hypertens (Greenwich). 2017;19(11):1137-1142. doi: 10.1111/jch.13083.

7. Varon J, Williams EJ. Management of severe asymptomatic hypertension (hypertensive urgencies) in adults. In: Post T, ed. UpToDate, Waltham, MA. (Accessed February 13, 2018)

8. Effects of treatment on morbidity in hypertension. Results in patients with diastolic blood pressures averaging 115 through $129 \mathrm{~mm} \mathrm{Hg}$. JAMA. 1967;202(11):1028-1034. soi: 10.1001/jama.1967.03130240070013

9. Patel KK, Young L, Howell EH, et al. Characteristics and outcomes of patients presenting with hypertensive urgency in the office setting. JAMA Intern Med. 2016;176(7):981-988. doi: 10.1001/jamainternmed.2016.1509.

10. MacDougall JD, Tuxen D, Sale DG, Moroz JR, Sutton JR. Arterial blood pressure response to heavy resistance exercise. J Appl Physiol. 1985;58(3):785790. doi: 10.1152/jappl.1985.58.3.785.

11. Strandgaard S, Olesen J, Skinhoj E, Lassen NA. Autoregulation of brain circulation in severe arterial hypertension. Br Med J. 1973;1(5852):507-510. doi: 10.1136/bmj.1.5852.507

12. Fischberg GM, Lozano E, Rajamani K, Ameriso S, Fisher MJ. Stroke precipitated by moderate blood pressure reduction. J Emerg Med. 2000;19(4):339346. doi: 10.1016/S0736-4679(00)00267-5.

13. Ross RS. Pathophysiology of coronary circulation. Br Heart J. 1971;33(2):173184. doi: $10.1136 /$ hrt.33.2.173

14. Brooks TW, Finch CK, Lobo BL, Deaton PR, Varner CF. Blood pressure management in acute hypertensive emergency. Am J Health Syst Pharm. 2007;64(24):2579-2582. doi: 10.2146/ajhp070105.

15. Grossman E, Messerli FH, Grodzicki T, Kowey P. Should a moratorium be placed on sublingual nifedipine capsules given for hypertensive emergencies and pseudoemergencies? JAMA. 1996;276(16):1328-1331. doi: 10.1001/ jama.1996.03540160050032

16. Hodsman GP, Isles CG, Murray GD et al. Factors related to first dose hypotensive effect of captopril: prediction and treatment. Br Med J (Clin Res Ed). 1983;286(6368):832-834. doi: 10.1136/bmj.286.6368.832.

17. Zeller KR, Von Kuhnert L, Matthews C. Rapid reduction of severe asymptomatic hypertension. A prospective, controlled trial. Arch Intern Med. 1989;149(10):2186-2189. doi: 10.1001/archinte.149.10.2186.

18. Pickering TG, Hall JE, Appel LJ, et al. Recommendations for blood pressure measurement in humans and experimental animals: Part 1: Blood pressure measurement in humans: a statement for professionals from the Subcommittee of Professional and Public Education of the American Heart Association Council on High Blood Pressure Research. Circulation. 2005;111(5):697-716. doi: 10.1161/01.CIR.0000154900.76284.F6.

19. Chobanian AV, Bakris GL, Black HR, et al. The seventh Report of the Joint National Committee on Prevention, Detection, Evaluation, and Treatment of High blood pressure: the JNC 7 report. JAMA. 2003;289(19):2560-2572. doi: 10.1001/jama.289.19.2560.

20. James PA, Oparil S, Carter BL, et al. 2014 evidence-based guideline for the management of high blood pressure in adults: report from the panel members appointed to the Eighth Joint National Committee (JNC 8). JAMA. 2014;311(5):507-520. doi: 10.1001/jama.2013.284427

21. Whelton PK, Carey RM, Aronow WS, et al. ACC/AHA/AAPA/ABC/ACPM/ AGS/APhA/ASH/ASPC/NMA/PCNA guideline for the Prevention, detection, evaluation, and management of High blood pressure in adults: A report of the American College of Cardiology/American Heart Association Task Force on Clinical Practice Guidelines. J Am Coll Cardiol. 2017.

22. Axon RN, Turner M, Buckley R. An update on inpatient hypertension management. Curr Cardiol Rep. 2015;17(11):94. doi: 10.1007/s11886-015-0648-y.

23. Grassi D, O'Flaherty M, Pellizzari $M$, et al. Hypertensive urgencies in the emergency department: evaluating blood pressure response to rest and to antihypertensive drugs with different profiles. J Clin Hypertens (Greenwich). 2008;10(9):662-667. doi: 10.1111/j.1751-7176.2008.00001.x.

24. Park SK, Lee DY, Kim WJ, et al. Comparing the clinical efficacy of resting and antihypertensive medication in patients of hypertensive urgency: a randomized, control trial. J Hypertens. 2017;35(7):1474-1480. doi: 10.1097/ HJH.0000000000001340.

25. Steinman MA, Auerbach AD. Managing chronic disease in hospitalized patients. JAMA Intern Med. 2013;173(20):1857-1858. doi: 10.1001/jamainternmed.2013.9511.

26. Breu AC, Allen-Dicker J, Mueller S et al. Hospitalist and primary care physician perspectives on medication management of chronic conditions for hospitalized patients. J Hosp Med. 2014;9(5):303-309. doi: 10.1002/jhm.2137. 